
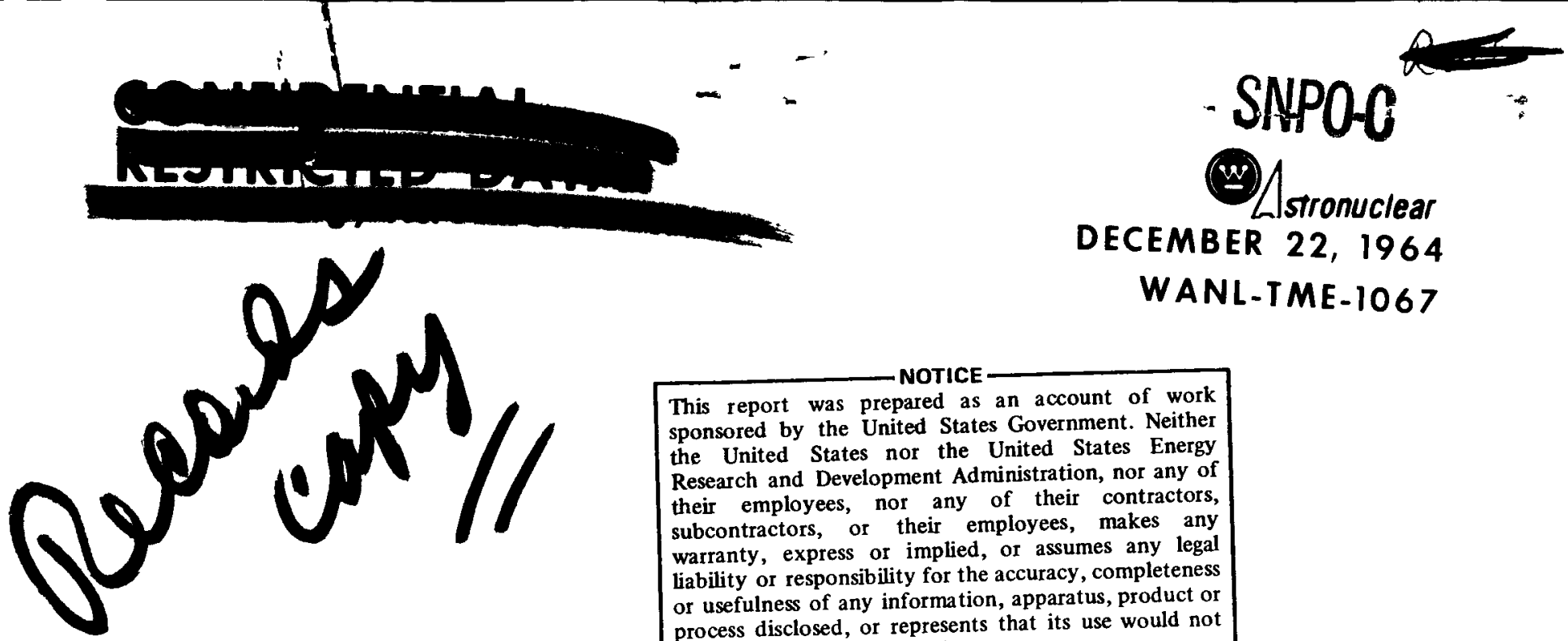

DECEMBER 22, 1964

WANL-TME-1067

\title{
LONG LIFE FUEL DEVELOPMENT PROGRAM
}

This report was prepared as an account of work sponsored by the United States Government. Neither the United States nor the United States Energy Research and Development Administration, nor any of their employees, nor any of their contractors, subcontractors, or their employees, makes any warranty, express or implied, or assumes any legal liability or responsibility for the accuracy, completeness or usefulness of any information, apparatus, product or process disclosed, or represents that its use would not infringe privately owned rights. 


\section{DISCLAIMER}

This report was prepared as an account of work sponsored by an agency of the United States Government. Neither the United States Government nor any agency Thereof, nor any of their employees, makes any warranty, express or implied, or assumes any legal liability or responsibility for the accuracy, completeness, or usefulness of any information, apparatus, product, or process disclosed, or represents that its use would not infringe privately owned rights. Reference herein to any specific commercial product, process, or service by trade name, trademark, manufacturer, or otherwise does not necessarily constitute or imply its endorsement, recommendation, or favoring by the United States Government or any agency thereof. The views and opinions of authors expressed herein do not necessarily state or reflect those of the United States Government or any agency thereof. 


\section{DISCLAIMER}

Portions of this document may be illegible in electronic image products. Images are produced from the best available original document. 


\section{LONG LIFE FUEL DEVELOPMENT PROGRAM}

\section{INTRODUCTION}

The NERVA fuel development program for long life capability fuel elements will be described. It is particularly significant to examine this program at this time in the light of three major achievements in the nuclear rocket program. The three achievements are:

1. Successful operation and restart of the KIWI-B4E

2. Successful operation of the NRX-A2

3. Laboratory demonstration of fuel element lifetimes of 20-30 minutes

One of the major conclusions which emerges from an evaluation of these achievements is that hydrogen corrosion atrack of graphite is one of the basic problems limiting the operational lifetime of NERVA reactors and that fuel development activities may be expected to increase the reactor lifetime. The specific goal of the long life development program is multi-cycle operation for total times of $60-120$ minutes.

The general approach adopted in the formulation of the long life development program involves detailed examination of the nature of the hydrogen corrosion problem and consideration of development activities to solve various aspects of the problem. The fuel element corrosion problem can be divided into four areas:

1. Corrosion within the coated coolant channels

2. Corrosion on end and side face coatings

3. Corrosion on external surfaces

4. Corrosion test problems 
The discussion of each of these problems and the appropriate development activities will follow a brief review of available corrosion data. It should be noted that the present discussion will not include an examination of the production and quality control difficulties which might be expected to occur in converting developmental solutions into practice.

\section{REVIEW OF FUEL ELEMENT CORROSION DATA}

\section{A. Data Summary}

Figure 1 presents a summary of hydrogen corrosion data obtained on NRX-A3 fuel elements produced at the Westinghouse Astrofuel Facility (WAFF). The overlap of the data for the various test conditions represents element-to-element variability and test temperature variability and uncertainty. Figure 2 shows the individual data points obtained in the IB test (surface temperature $2200^{\circ} \mathrm{C}$ and approximate maximum material temperature $2500^{\circ} \mathrm{C}$ ). Also shown on Figure 2 are the data obtained on NRX-A3 fuel elements at Los Alamos Scientific Laboratory ${ }^{l}$ in orificed tests at surface temperatures of $2250^{\circ} \mathrm{C}$ (maximum material temperature approximately $2400^{\circ} \mathrm{C}$ ). The $\mathrm{IB}$ data points indicated as $(10+10)$ in Figure 2 were obtained in two 10-minute cycles which involved removal of the fuel element from the corrosion test facility. The data shown in Figures 1 and 2 provide the basis for the conclusion that present NERVA fuel elements have a 20-30 minute full power operational capability.

The corrosion data shown in Figures 1 and 2 have been analyzed in terms of the two major mechanisms of carbon weight loss; i. e., mid-range and high temperature corrosion. The results of this analysis will be reviewed briefly.

1L. L. Lyon, et al, "Hydrogen Corrosion Tests of NERVA Elements, " November, 1964, $N-1-1426$.

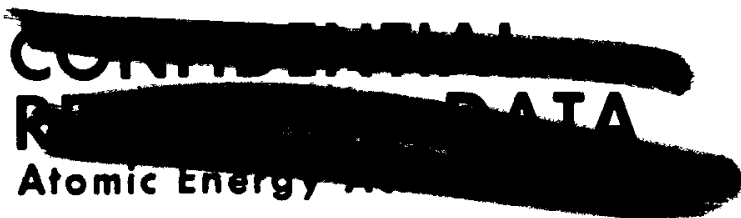



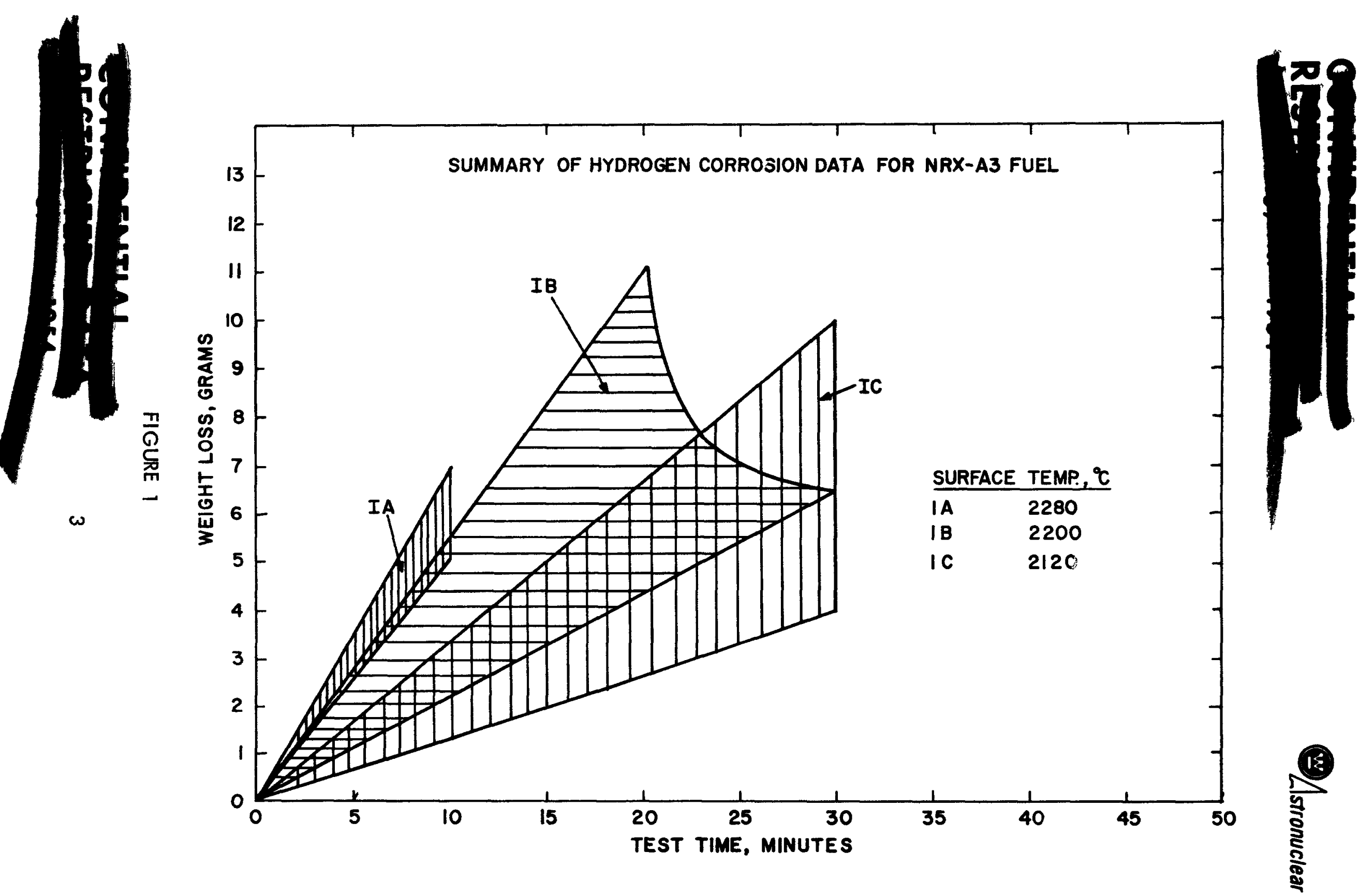

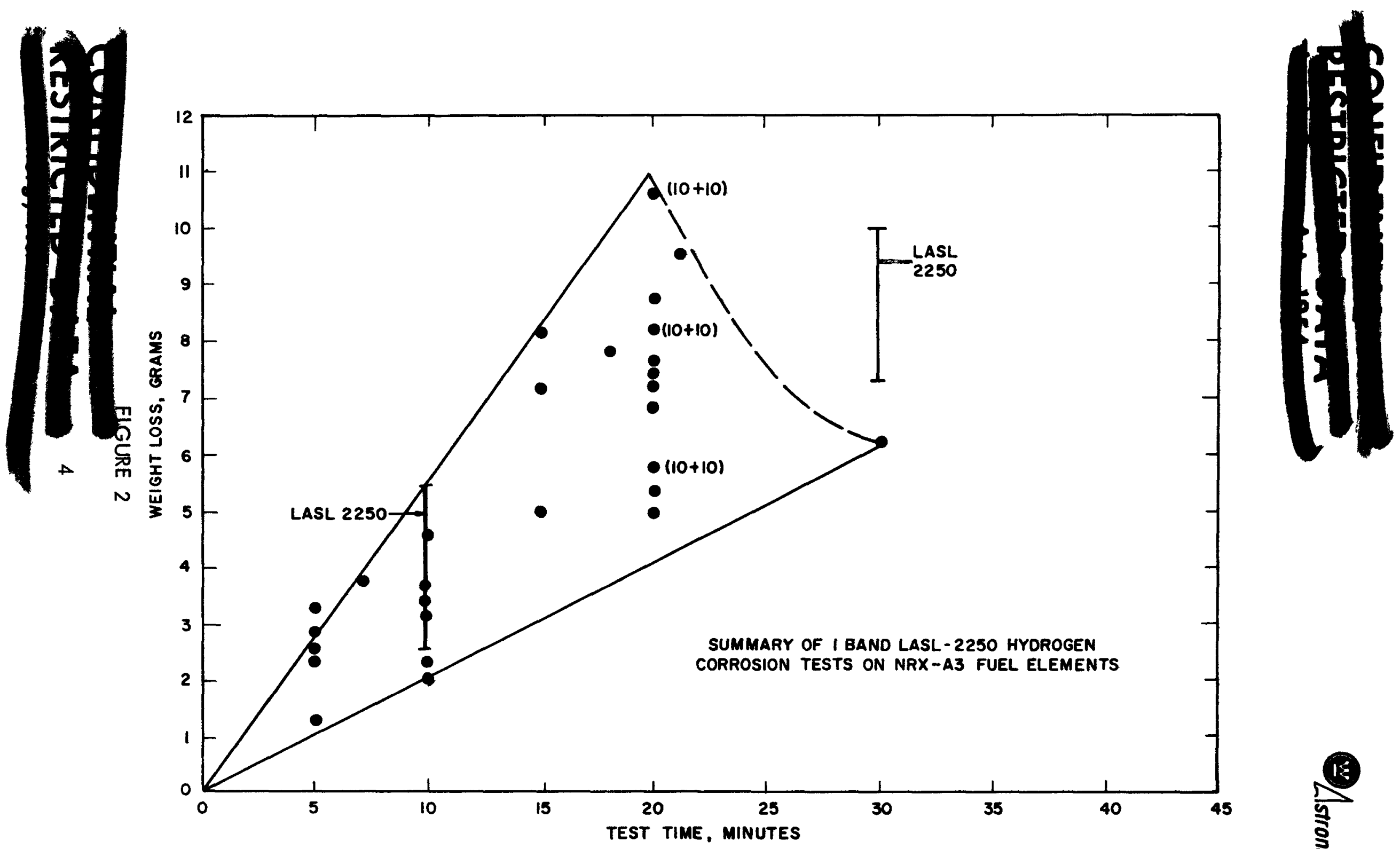

$\frac{1}{3}$ 


\section{B. Analysis of Corrosion Data}

Recent preliminary data obtained on the corrosion of uncoated 52 inch long by 0.1 inch diameter channels of fueled graphite indicate a corrosion rate given by the following equation*:

$$
M=7 \times 10^{5} \exp (-30,000 / R T)
$$

where $M$ is the corrosion rate of the channel in mils per hour, $R$ the gas constant, and $T$ the temperature in ${ }^{\circ} K$. Thus, uncoated fuel element channels would be expected to show a small amount of corrosion at $1000^{\circ} \mathrm{C}$ (6 mils/hour) and considerable corrosion at $1400^{\circ} \mathrm{C}$ (100 mils/hour). Fueled graphite coated with $\mathrm{NbC}$ shows evidence of hydrogen corrosion between 1300 and $1800^{\circ} \mathrm{C}$, particularly in the vicinity of cracks in the $\mathrm{NbC}$ coating. The corrosion appears locally as undercutting of the graphite beneath cracks in the coating. The cracks are present as a direct consequence of the difference in the coefficient of thermal expansion between the $\mathrm{NbC}$ coating (approximately $7 \times 10^{-6}$ per ${ }^{\circ} \mathrm{C}$ ) and the fueled graphite substrate (approximately $4 \times 10^{-6}$ per ${ }^{\circ} \mathrm{C}$ ). The cracks are apparently closed in regions of the fuel element operated at temperatures above the temperature used in vapor deposition of the coating, i.e., $1900^{\circ} \mathrm{C}$.

The equation used to describe carbon weight loss by mid-range corrosion at a given temperature is given below:

$$
\Delta w_{L}=k_{L}\left(T_{C}-T\right) \exp (-30,000 / R T)
$$

where $\Delta w_{L}$ is the weight loss in grams per minute per unit length, $k_{L}$ a constant dependent on the difference in thermal expansion coefficients of the coating and substrate and processing variables, $T_{c}$ is the effective $\mathrm{NbC}$ coating temperature for the middle of the fuel element, and $\mathrm{T}$ the local test temperature in ${ }^{\circ} \mathrm{K}$. Sufficient data are not yet

\footnotetext{
* The corrosion rate given in equation (1) is approximately a factor of 4 higher than that
} given in WANL-TME-432, July, 1963. 
available to make good estimates of $k_{L}$. The total (per element) weight loss due to midrange corrosion, $\Delta w_{L^{\prime}}$ is obtained by integrating the weight loss over the length of fuel element at temperatures from $800^{\circ} \mathrm{C}$ to $\mathrm{T}_{\mathrm{c}}$. Preliminary integrated weight loss values for $\Delta W_{L}$ of $0.20-0.25$ grams per minute have been determined as will be shown in later discussion.

At temperatures above the nominal $1900^{\circ} \mathrm{C} \mathrm{NbC}$ coating temperature the mechanism of hydrogen attack of coated graphite involves decarburization of the $\mathrm{NbC}$ coating and subsequent diffusion of carbon through the coating as well as local corrosion at defects in the NbC coating. The decarburization mechanism is controlled by the rate of carbon diffusion through $\mathrm{NbC}$ and can be described by the following equations. The flux, $J$ (grams per second) of carbon through the coating is given by:

$$
J=-D A \quad \frac{\delta c}{\delta x}
$$

where $D$ is the diffusion coefficient for carbon in $\mathrm{NbC}$ in square centimeters per second, $A$ is the area, and $\delta c / \delta x$ is the carbon concentration gradient with in the $\mathrm{NbC}$ coating expressed in grams per cubic centimeter. D is a function of temperature and has been determined recently by Brizes and Cadoff ${ }^{2}$ :

$$
D=1.0 \exp (-76,000 / R T)
$$

The concentration gradient $\delta_{c} / \delta_{x}$ depends on coating thickness and $\mathrm{C} / \mathrm{Nb}$ stoichiometry at the graphite-coating interface and the coating-hydrogen surface. Generally, the $\mathrm{C} / \mathrm{Nb}$ ratio at the graphite-coating interface is 0.93 at the hot end of fuel elements after

2W. Brizes and L. Cadoff, WANL-TNR-185, November, 1964.

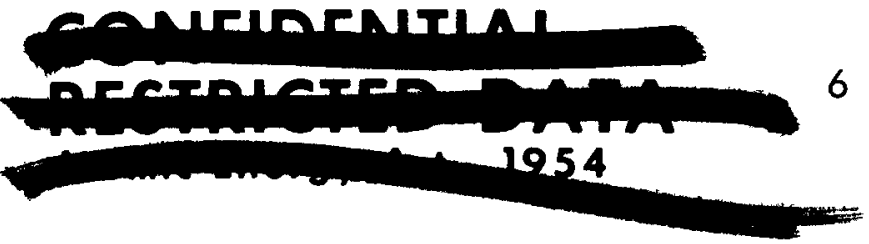


a corrosion test. The stoichiometry of $\mathrm{NbC}$ coating at the coating-hydrogen surface varies

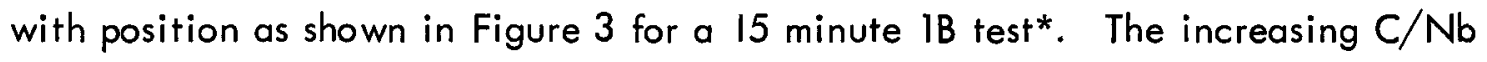
stoichiometry from 30 inches to the hot end of the fuel element is apparently due to increasing carbon concentration in the gas stream.

The equation describing the decarburization weight loss at a given temperature is as follows:

$$
\Delta w_{H}=k_{H} \exp (-76,000 / R T)
$$

where $\Delta w_{H}$ is the weight loss in grams per minute per unit length, $k_{H}$ a constant dependent on $\mathrm{NbC}$ coating thickness and carbon concentration gradient, and $\mathrm{T}$ the tes iemperature in ${ }^{\circ} \mathrm{K}$. The total (per element) weight loss, $\Delta \mathrm{W}_{\mathrm{H}^{\prime}}$ due to decarburization corrosion is obtained by integrating the weight loss, $\Delta w_{H^{\prime}}$ over the length of fuel element at temperatures above $1900^{\circ} \mathrm{C}$. Preliminary integrated weight loss values for $\Delta W_{H}$ for the IA, IB, and IC corrosion test have been calculated and are given in Table I. It should be noted that the calculation of $\Delta W_{H}$ is highly dependent on the axial temperature profile for each of the 19 coolant channels**.

Table I also summarizes the experimentally determined total weight loss for $1 A, I B$, and $I C$ corrosion tests. The values of $\Delta W_{L}$ given in Table I were computed from the following equation:

$$
\Delta W_{T}=\Delta W_{H}+\Delta W_{L}
$$

*Results obtained by L. Cadoff, WANL. An unexpected result of these experiments was the presence of coating material with lattice parameter significantly lower than that reported for stable non-stoichiometric $\mathrm{NbC}_{0 .} 7^{\circ}$

**The results of this calculation must be considered tentative due to the uncertainty of the axial temperature profile in the three types of corrosion tests. 

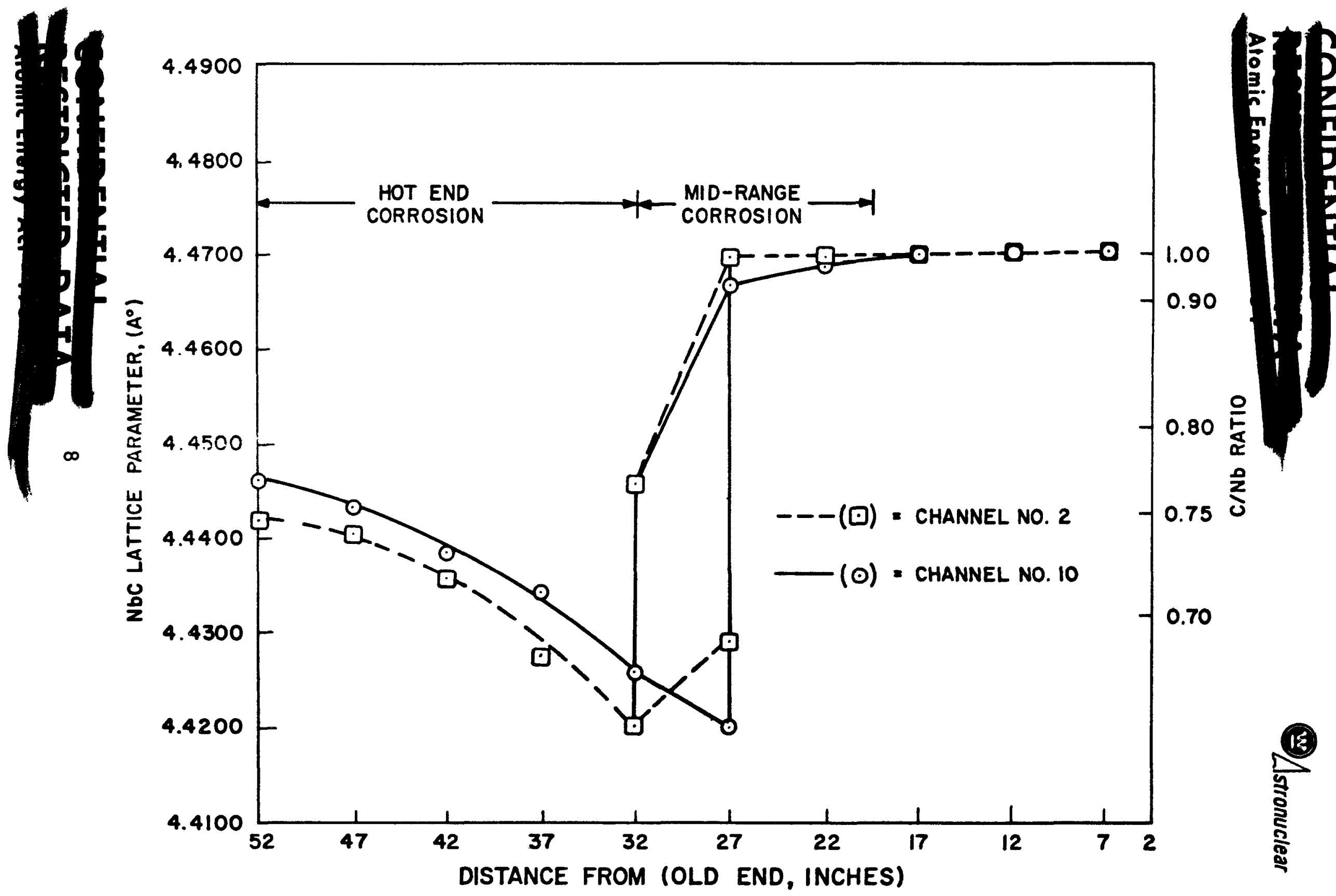
TAB LE I. Quantitative Analysis of Hydrogen Corrosion Results

Weight Loss per Unit Time grams/minute

\begin{tabular}{|c|c|c|c|c|}
\hline \multirow[b]{2}{*}{$\begin{array}{l}\text { Corrosion } \\
\text { Test }\end{array}$} & \multicolumn{3}{|c|}{ grams/ minure } & \\
\hline & $\begin{array}{c}\text { Total Measured } \\
\qquad \Delta W_{T}\end{array}$ & $\begin{array}{l}\text { High Temperature } \\
\Delta W_{\text {if }}^{*}\end{array}$ & $\begin{array}{l}\text { Low Temperature } \\
\Delta W_{L}^{* *}\end{array}$ & $\frac{\Delta W_{L}}{\Delta W_{T}} \times 10$ \\
\hline $1 A$ & 0.6 & 0.35 & 0.25 & 42 \\
\hline $1 \mathrm{~B}$ & 0.36 & 0.13 & 0.23 & 64 \\
\hline $1 \mathrm{C}$ & 0.27 & 0.05 & 0.22 & 82 \\
\hline
\end{tabular}

*Calculated from corrosion model

$* * \Delta W_{L}=\Delta W_{T}-\Delta W_{H}$

where $\Delta W_{T}$ is the total weight loss measured in grams per minute for a particular corrosion test.

The major conclusion resulting from this analysis is that mid-range corrosion accounts for a large fraction of the total weight loss in the three types of corrosion tests. Furthermore, the weight loss for fuel elements operating at nominal reactor temperatures (below IC conditions) will result primarily from mid-range corrosion. Thus, improvement in the performance of the $\mathrm{NbC}$ coating at the center of fuel elements should result in significantly lower over-all fuel element weight loss.

Metallographic evidence for the corrosion analysis is shown in Figure 4. The transverse microstructures shown were obtained on a fuel element tested for 30 minutes at IC condition. The total weight loss was 9.8 grams. Several interesting observations are given below:

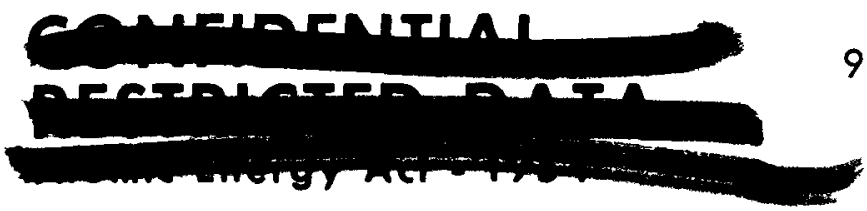




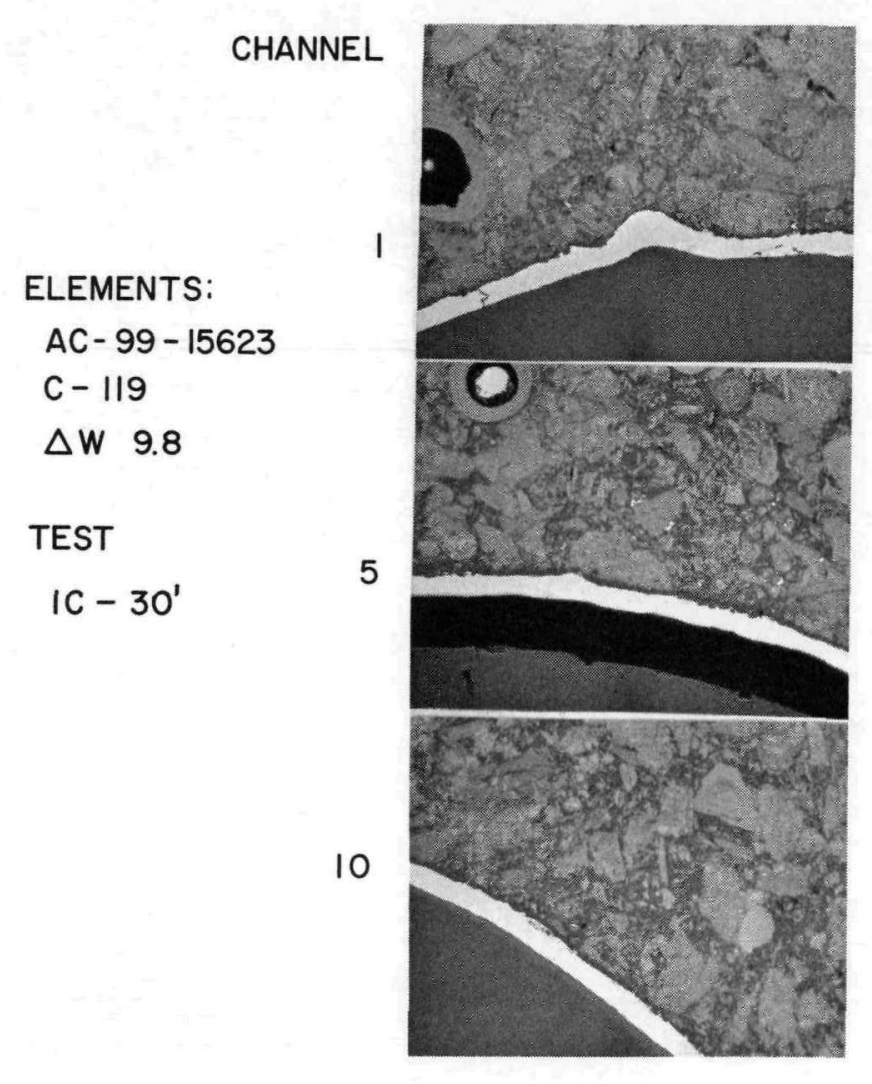

20

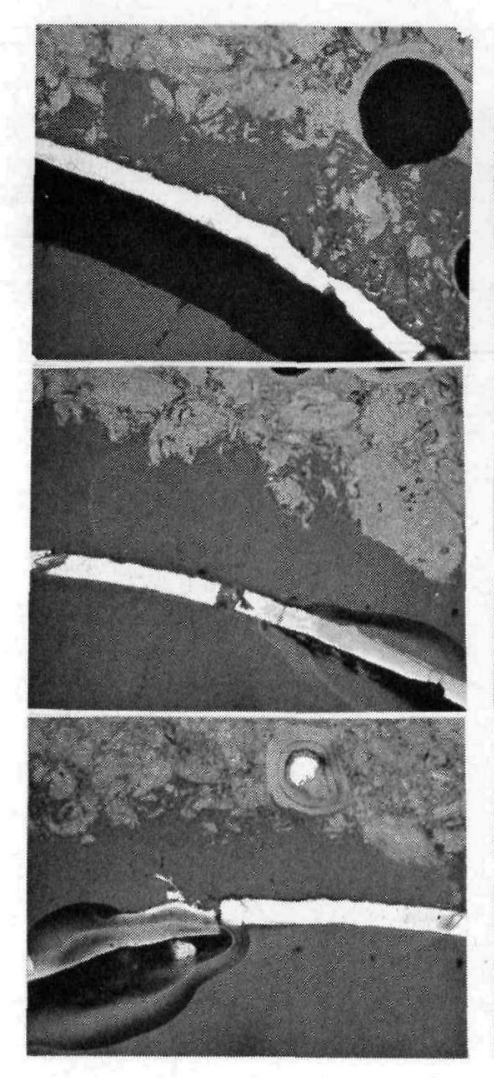

25

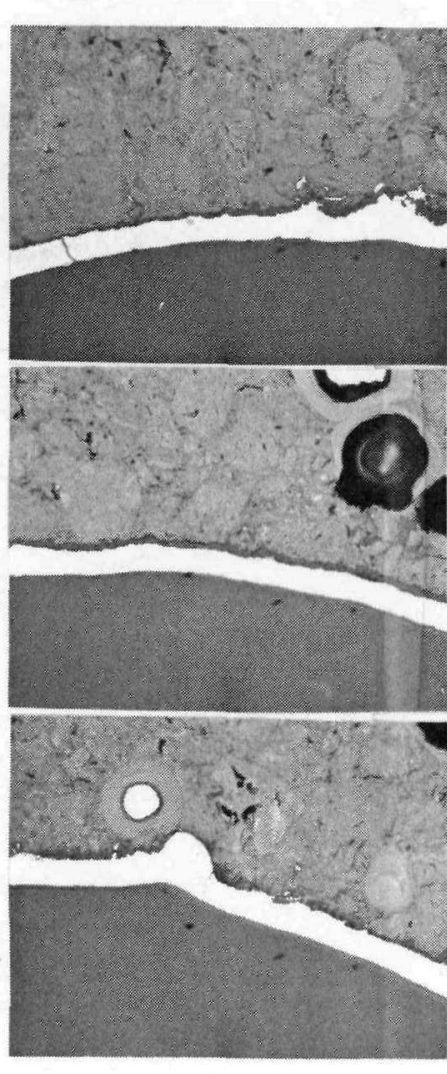

30

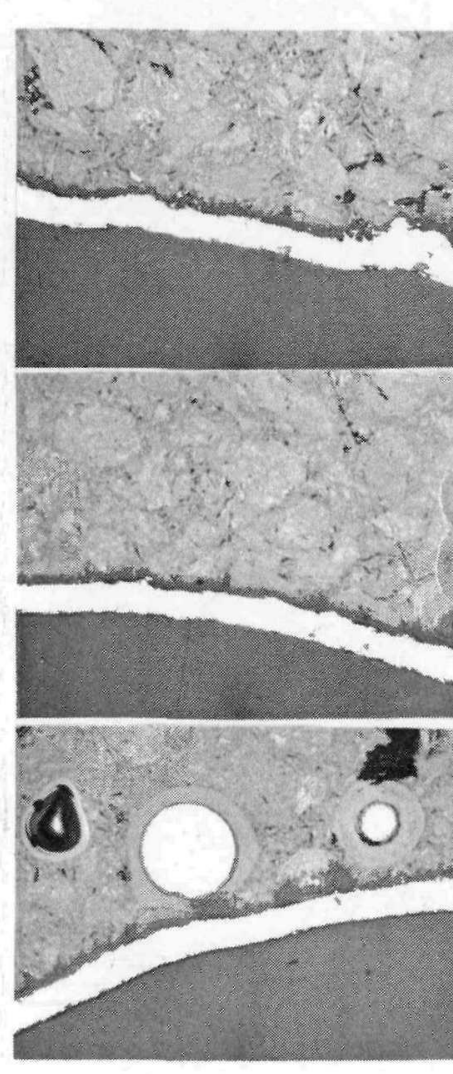

35

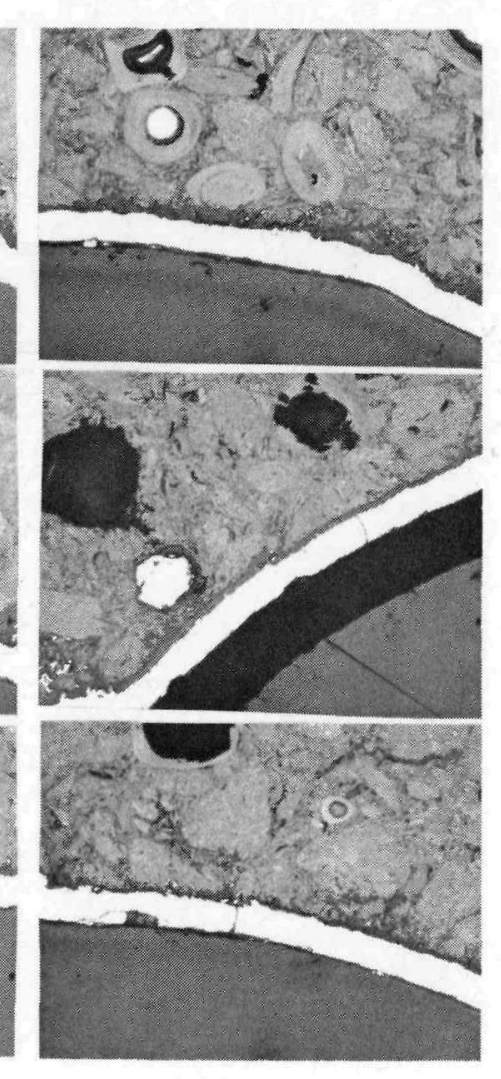

40

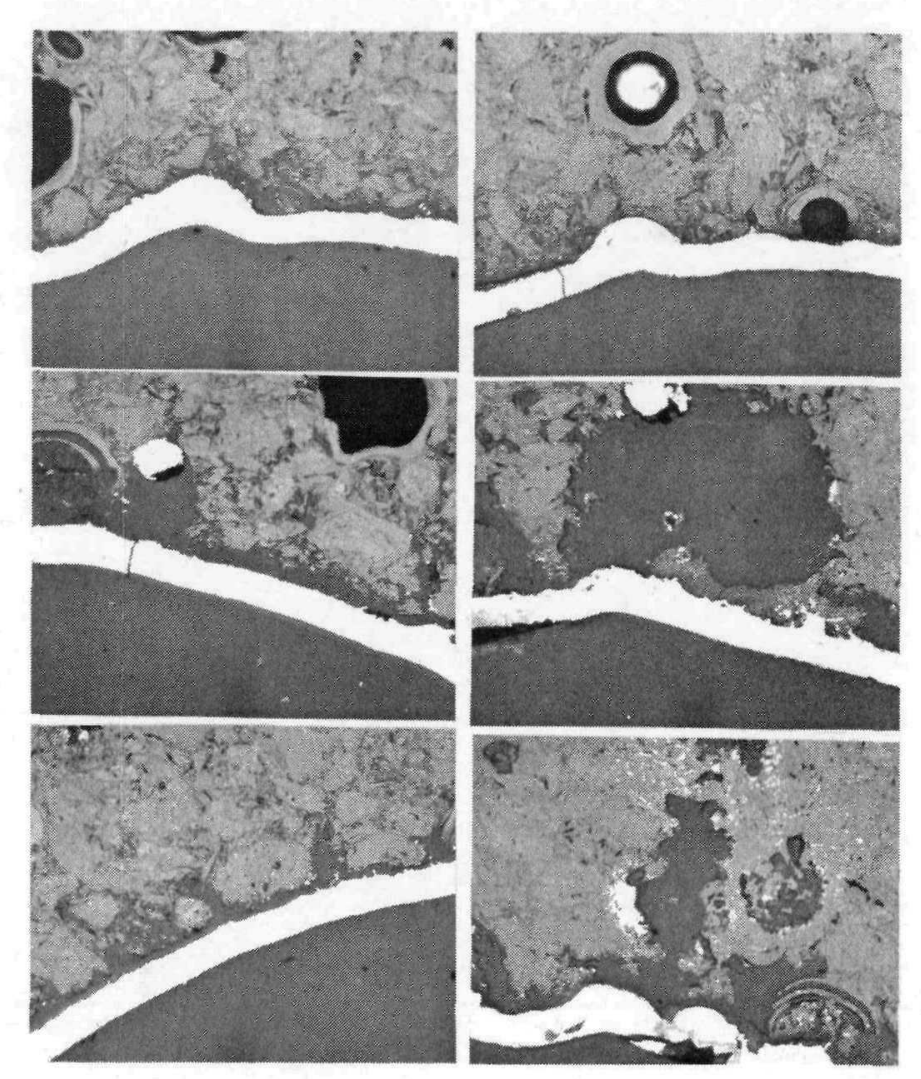

45 
1. At 20 inches from the cold end, evidence for preferential corrosion of the binder carbon can be seen.

2. At 25 inches, mid-range corrosion effects appear as general attack of the graphite substrate.

3. Evidence for high temperature corrosion appears at 45 inches.

4. Local high temperature corrosion is visible at 49 inches. This effect is believed to be associated with local hot spots occurring in the vicinity of the chuck used to hold the element.

\section{LONG LIFE DEVELOPMENT PROGRAM}

\section{A. Bore Coatings}

The bore coating development program is divided into two parts. The first relates primarily to improvements in the performance of elements with respect to midrange corrosion. The second is a more general coating development program with some specific application to the high temperature corrosion problem.

The obvious direct attack on the mid-range corrosion problem involves the elimination of the cracks in the $\mathrm{NbC}$ coating. This can be accomplished by providing a fueled graphite substrate that has a thermal expansion coefficient nearly like that of $\mathrm{NbC}$. The alternate approach of developing a refractory metal carbide coating which matches the expansion coefficient of the present fueled graphite is considered to be a less likely solution to the problem. The concept of developing a graphite substrate to match the $\mathrm{NbC}$ expansion coefficient has been worked on for some time. However, not until recent Air Force sponsored work by Union Carbide Corporation has this approach appeared feasible $e^{3,4}$. The work by Union Carbide indicates the promising

${ }^{3}$ WADD-TR-61-72, Vol. XIII and Supplement.

${ }^{4}$ Union Carbide Corporation Quarterly Progress Report, August 15, 1963.

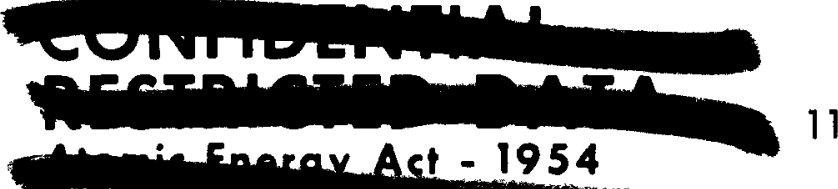




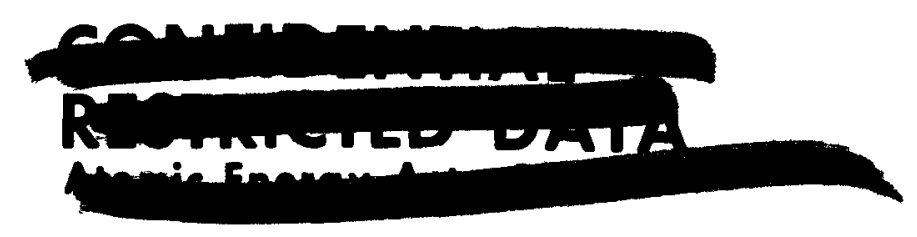

development of an isotropic petroleum coke and subsequent processing of this coke to produce graphite flour which can be used to make extruded bodies of high thermal expansion coefficient. The key factor in the Union Carbide program is the development of controlled techniques for coking petroleum. It is expected that modest quantities of experimental batches of the isotropic flour will be available for laboratory and pre-production experiments in the period January-July, 1965. It is not known at present when reactor core quantities of this material could be available, should the experimental program be successful.

The laboratory pre-production experiments on experimental batches of isotropic petroleum flour would include the following activities:

\section{Material Characterization}

Surface area, surface chemistry, particle size and shape, wetability, acidity $(\mathrm{pH})$, chemical analysis, porosity and pore distribution, crystallinity, crystallite size, and density.

\section{Fabrication Evaluation}

Interaction with binder, extrusion characteristics, processing conditions in cure, bake, graphitization, leaching, and vapor deposition, control of mechanical defects.

\section{Properties of Fabricated Bodies}

Thermal expansion, thermal conductivity, electrical resistance, density, mechanical properties, radiation damage sensitivity, hydrogen corrosion behavior, preferred orientation, and structure. 
Concurrent with the activities described above, exploratory programs will be carried out on other potential sources of high expansion graphites. The principal approaches of this exploratory work involve:

1. Evaluation of commercially available high expansion graphites. Material under investigation includes fluid coke (Gulf) and "gilso-carbon."

2. Evaluation of mechanical and physical properties of extruded bodies made from isotropic pyrocarbon spheres.

3. Evaluation of experimental isotropic graphites made by graphitizing spherical lampblack.

It is recognized that the direct approach on the mid-range corrosion problem may require considerable effort before high expansion graphite flour will be available for fuel element production. Accordingly, several shorter range approaches will be pursued which may also be expected to yield significant improvements in fuel element performance. The shorter range programs are described below:

1. Develop coating processes which permit the use of low coating temperatures on the mid-section of fuel elements. According to equation (2) this will shift the mid-range corrosion problems toward the cold end of the fuel element*.

2. Develop a two-step coating process to heal cracks in the middle of the fuel element or to shift mid-range corrosion toward the cold end of the fuel element.

3. Minimize mid-range corrosion by parametric study of the influence of processing variables (coating thickness, coating rate, coating temperature, etc.) on extent of mid-range corrosion.

*M. Blinn performed an analysis of the potential benefit which may be expected by coating the mid-section of fuel elements at $1600^{\circ} \mathrm{C}$. The preliminary results indicate that mid-range corrosion could be reduced by a factor of 3-4.

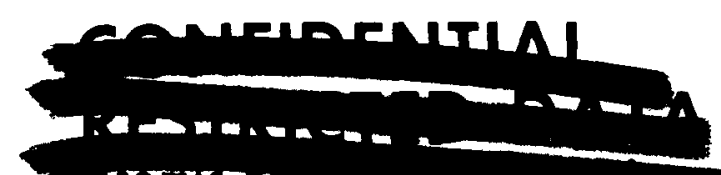




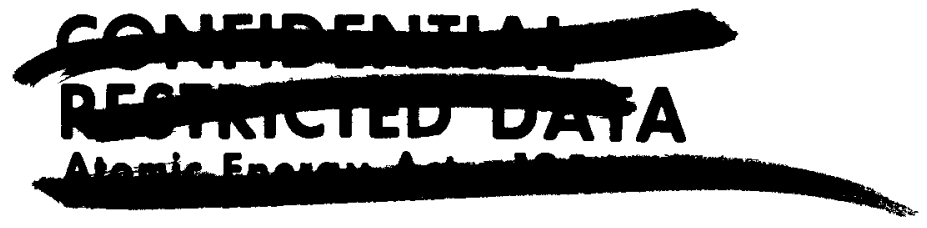

The shorter range programs described above will be performed in the pilot plant at Westinghouse Astronuclear Laboratory (WANL)* and at WAFF throughout NRX-A4 fuel element production. Corrosion studies of developmental coating batches will also be performed concurrent with NRX-A4 quality control testing.

The second part of the development program to improve bore coatings involves careful examination of many phases of fuel element processing. Several of the significant features of this program are outlined below:

1. Examine influence of higher graphitization temperatures on performance of fuel elements. Particular attention will be given to hydrogen corrosion behavior and dimensional stability.

2. Examine influence of higher coating temperatures on performance of fuel elements. This development is specifically aimed at improvement of the performance of the hot end of fuel elements. Development activities during NRX-A3 production revealed advantages in coating at $2000^{\circ} \mathrm{C}$ as compared to $1900^{\circ} \mathrm{C}$. Careful attention must be given to effect of coating temperature on performance of end and side coating on fuel elements.

3. Evaluation of performance of extruded-to-size fuel elements. The major advantage of extruded-to-size elements will be the reduction in processing operations (reaming and leaching would be eliminated). However, some benefit to the high temperature corrosion behavior may also be realized.

4. Parametric study of coating gas chemistry on fuel element performance. Particular interest centers on elimination of $\mathrm{HCl}$ from the gas stream, concentration ratio of hydrogen to salt, and value of methane additions.

5. Effect of $\mathrm{HCl}$ leaching prior to coating on fuel element performance. Development coating runs performed between NRX-A2 and NRX-A3

*Pilot plant operation will be underway in January, 1965. 
production work revealed that corrosion behavior of unleached fuel elements was essentially equivalent to leached elements. Consideration must be given to uranium loading effects, substrate behavior and corrosion behavior.

6. Optimization of $\mathrm{NbC}$ coating thickness profiles relative to fuel element performance. Determine optimum $\mathrm{NbC}$ thickness on hot end of fuel elements.

7. Perform exploratory coating studies involving $\mathrm{ZrC}, \mathrm{TaC}$ and pyrolytic graphite. Principal purpose of this program is to develop process capability and provide small number of samples for corrosion evaluation. It is interesting to note the preliminary data shown in Figure 5 on the comparative diffusion rates of carbon in $\mathrm{NbC}^{*}$, $\mathrm{ZrC}^{* *}$, and $\mathrm{TaC}^{* * *}$. The results indicate that carbon diffusion rates in $\mathrm{NbC}$ and $\mathrm{ZrC}$ are quite similar whereas carbon diffusion rates in $\mathrm{TaC}$ may be an order of magnitude lower. This result indicates that substitution of $\mathrm{TaC}$ for $\mathrm{NbC}$ at the high temperature end of fuel elements would improve performance, whereas substitution of $\mathrm{ZrC}$ for $\mathrm{NbC}$ at the lower temperature regions of fuel elements would not be expected to affect performance.

\section{B. End Coating Development}

Development and production work at WANL, LASL, and $Y-12$ have shown that it is difficult to produce adherent coatings on the end and undercut side faces of fuel elements. The four methods employed to produce end and side coatings include:

1. One step coating process with careful control of end temperature and coating gas (NRX-A2 production).

2. One step coating process with methane additions to the coating gas (LASL development).

3. One step coating process with unfueled tips cemented to the end of fuel elements (with and without methane).

\footnotetext{
* See reference (2).

** Studies performed by L. Adelsberg, WANL. $* * *$ Studies performed by W. Brizes, WANL.
} 


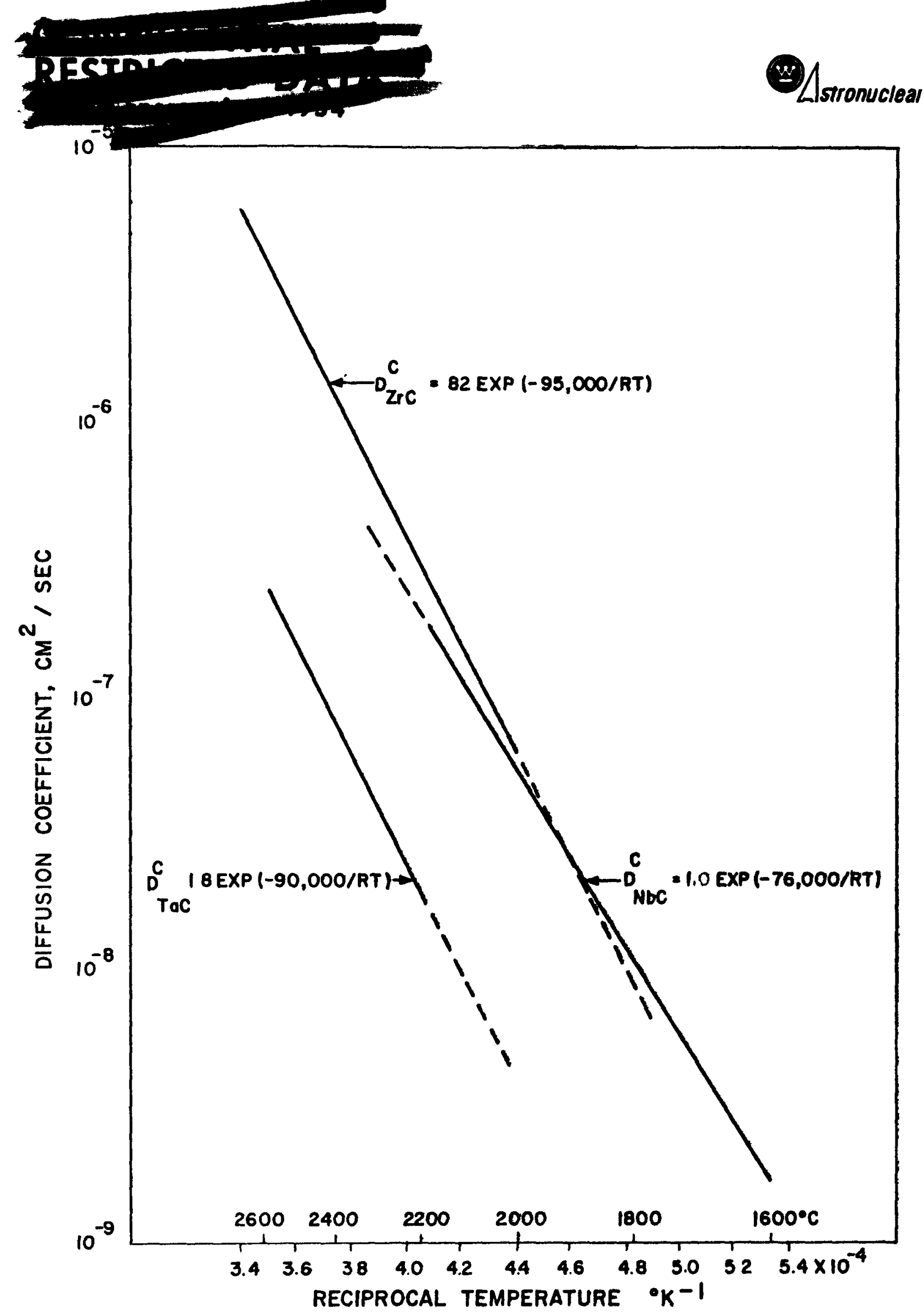

Alomictming 


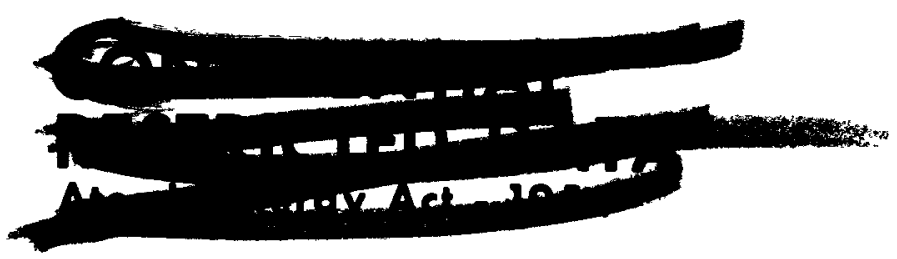

4. Two step coating process involving methane addition to the coating gas during the recoat cycle (LASL KIWI-B4E and $\mathrm{Y}-12$ NRX-A3).

With respect to the four methods described above, the most desirable end coatings are obtained by the one step coating process with cemented unfueled tips. End coatings produced by this process routinely pass the present WANL five minute IA test (surface temperature $2280^{\circ} \mathrm{C}$ ) and also behave satisfactorily in 15-30 minute IB and IC tests (surface temperatures $2200^{\circ} \mathrm{C}$ and $2120^{\circ} \mathrm{C}$, respectively). Corrosion tests of 60 minute duration at $\mathrm{IB}$ and $\mathrm{IC}$ conditions are planned.

The development work in progress relative to the end coat problem primarily involves improvement in the strength of the cemented joint. Results of initial development work, shown in Tables II and III indicate that the present cemented graphite joints are capable of satisfactory operation under the shear and flexure loads imposed on the joints. The development work planned or in progress includes:

1. Continue development of methods for producing stronger joints between fueled and unfueled graphite. This work would include joint design, cement types, and processing operations. Also under consideration are carbide brazing methods $(\mathrm{ZrC}, \mathrm{NbC}, \mathrm{WC}$, and $\mathrm{TaC}$ ).

2. Optimize $\mathrm{NbC}$ coating process with respect to end coat requirements. This work involves evaluation of corrosion performance of end coatings as a function of coating parameters (temperature, $\mathrm{NbC}$ thickness, fixturing geometry, and undercut configuration).

3. Continue development of coating process on fueled element ends. It may be expected that the development of high thermal expansion graphite will obviate the need for unfueled tips on fuel elements.

\section{External Surface Coating}

Examination of the fuel elements from the recent KIWI and NERVA tests indicate that significant corrosion attack occurs on the uncoated surfaces of peripheral

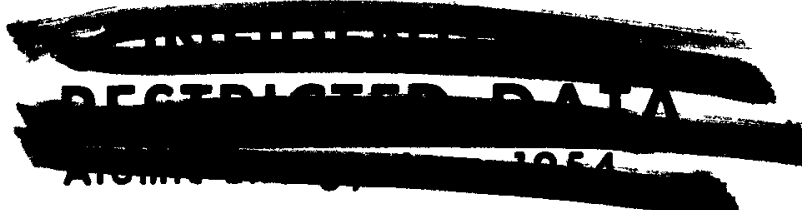




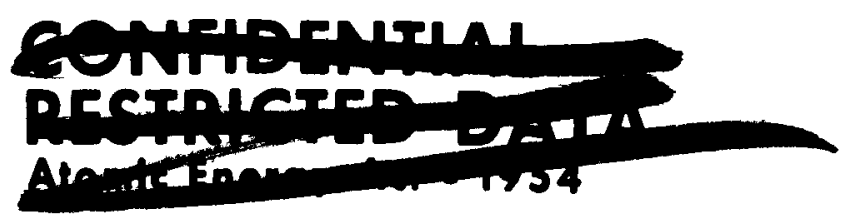

TABLE II. Flexure and Shear Data Fueled/Unfueled Joints

\begin{tabular}{lll}
\multicolumn{1}{c}{ Samples } & \multicolumn{2}{c}{ Average and Range } \\
\cline { 2 - 3 } Old Production Techniques & $\frac{\text { Four Point Flexure, psi }}{1700 ; 1290-2260(21) *}$ & $\frac{\text { Shear, psi }}{215-1066(15)}$ \\
New Production Techniques & $2440 ; 2440-2670(4)$ & $1700 ; 1390-2110(4)$ \\
Development & $2530 ; 2190-3330(13)$ & $1580 ; 1220-2050(20)$ \\
*Number of samples tested.
\end{tabular}

TABLE III. Three Point Flexure Data Fueled/Unfueled Joints

Average Flexure Strength and Range, psi

\begin{tabular}{cccc}
$\begin{array}{c}\text { Test } \\
\text { Temperature, }{ }^{\circ} \mathrm{C}\end{array}$ & $\begin{array}{c}\text { Development } \\
\text { Samples }\end{array}$ & \multicolumn{2}{c}{ Production Samples } \\
Room Temperature & $1660 ; 1460-1930(7)^{*}$ & Old & New \\
1700 & $4500 ; 4090-5100(4)$ \\
2100 & $4560 ; 3820-5050(7)$ & $3330 ; 2580-4070(3)$ & $6100 ; 5280-7150(3)$ \\
2400 & $5380 ; 4940-6100(u)$ & &
\end{tabular}

* Number of samples tested.

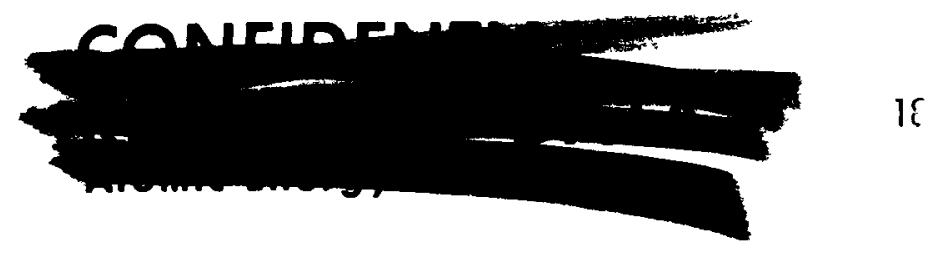


fuel elements. The general approach to the problem of corrosion attack on the uncoated surfaces of fuel elements involves minimization of hydrogen leakage to the core and coating of the external surfaces of the fuel elements. The minimization of leakage hydrogen is primarily a reactor design problem and will not be treated here. The materials of interest for protective coatings on the external fuel element surfaces include $\mathrm{NbC}$, $\mathrm{ZrC}$, and pyrolytic carbon. Preliminary work indicates that relatively thin external coatings (less than one mil thick) will provide the required corrosion protection.

Development work involving vapor deposited $\mathrm{NbC}$ external coatings was initiated at the end of NRX-A3 production to make peripheral fuel elements with 0.20.7 mil thick external $\mathrm{NbC}$ coatings*. Continued development of the external vapor deposition process is required for NRX-A4 and subsequent reactors. The principal problem encountered with external vapor deposition of fuel elements (previously bore coated) is related to bore coat degradation during the external coating operation. Preliminary work indicates the need for careful control of gas chemistry, flow rates, and furnace temperatures. Consideration should also be given to parallel flow coating as compared to the series flow now under development at WAFF.

An alternate approach to the problem of corrosion attack on the uncoated surfaces of fuel elements involves the introduction of methane (possibly formed by corrosion of sacrificial graphite) or helium into the peripheral and/or interstitial region of the core. Exploratory experiments are planned to evaluate this approach.

\section{Corrosion Test Program}

The primary goals of the long life corrosion test program are to evaluate the lifetime capability of fuel elements and to identify the limitations in fuel element

\footnotetext{
*Exploratory development work on plasma spray $\mathrm{ZrC}$ coatings was also performed. In general, the thin vapor deposited coating was superior in corrosion performance to the 2-3 mil plasma spray coating.
}

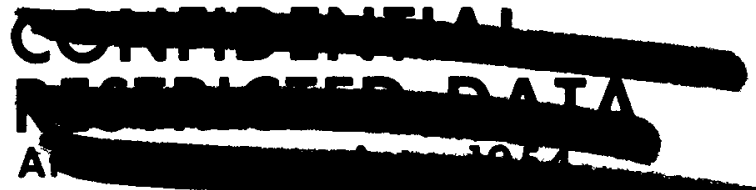


performance. Examples of several of the specific programs planned or underway are listed below:

1. Evaluate fuel element performance in multiple cycle corrosion tests for total times of 30-120 minutes. Initial long life testing will be peformed at $\mathrm{IB}$ and $\mathrm{IC}$ test conditions. Plans are also being made to initiate long life tests on orificed fuel elements.

2. Continue detailed evaluation of fuel element behavior in corrosion tests. The purpose of this work is to improve understanding of the mechanism of hydrogen corrosion of coated and uncoated graphite; contribute ideas to process development activities; and develop comparisons of reactor vs. electrical corrosion behavior.

3. Contribute to the solution of problems of long life corrosion tests:

\section{a. Electrical Aborts}

Available evidence indicates that fuel element characteristics and design of corrosion test apparatus influence frequency of electrical aborts. Particular fuel element characteristics under consideration include graphitization temperature, level of residual stress in fuel elements, number and size of mechanical defects, and graphite permeability. Further examination of chuck design, thermal radiation shielding, and rate of temperature rise during startup is planned.

\section{b. Mid-range Corrosion Problem}

It is anticipated that mid-range corrosion will lead to testing problems in the long life test program*. Special tests with pre-heated hydrogen may be required to extend test time to 60 minutes or more.

\section{c. Control Problems}

Electrical resistance data show large changes during corrosion testing which lead to alterations of power distribution within the

*LASL reports mid-range corrosion problems in test of 20-40 minute duration.

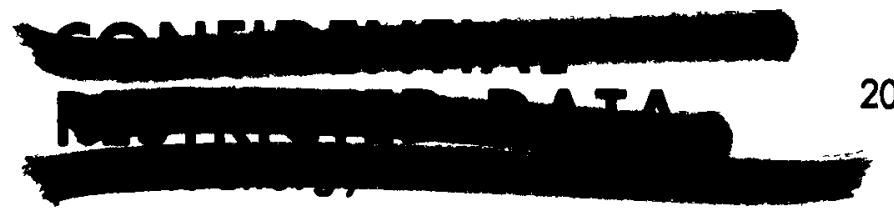



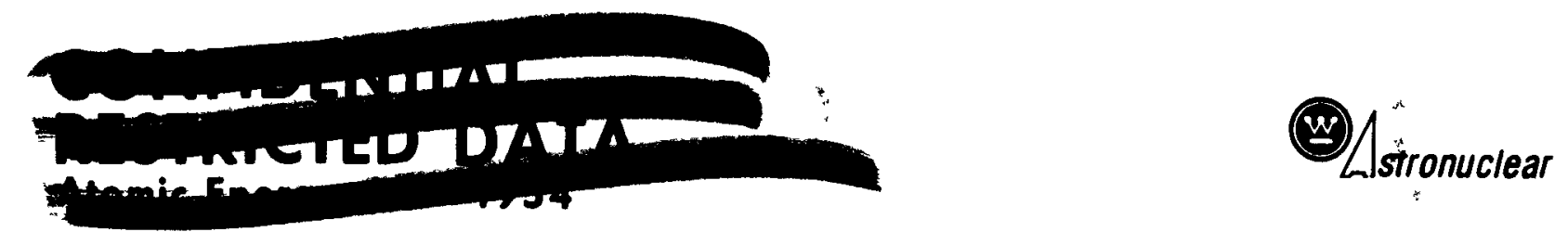

WANL-TME- 1067

fuel elements. Basic data on electrical resistance changes with temperature, time, and extent of corrosion are needed to permit reasonable control of test conditions.

4. Continue development of meaningful quality control tests of long life fuel elements. Determine minimum level of batch testing required to insure required level of reactor performance.

5. Continue assistance to Fluid Flow and Reactor Analysis groups in determination of temperature distribution during a corrosion test.

\section{CONCLUSION}

During the past 12 months considerable progress has been made in improvements to our understanding of corrosion behavior and fuel element processing and in the performance of production fuel elements. NRX-A3 fuel elements show average weight losses of 2.5 grams and essentially $100 \%$ (actual average is $95 \%$ ) of end coat remaining in a 5 minute $1 A$ test. This may be compared to an average weight loss of 3.5 grams and $50 \%$ end coat remaining for NRX-A2 elements tested under the same conditions. Also, NRX-A3 elements show average 20 minute IB weight losses of 7 grams and 20 minute 1C weight losses of 5.5 grams plus capability for multiple cycle operation. In light of this progress, it is recommended that continued attention be given to the development programs aimed at a 60-120 minute fuel element. 